\title{
Histórias em quadrinhos e storyboard: Uma análise comparativa
}

\section{Comic books and storyboard: A comparative analysis}

MANHÃES, Ricardo; M. Sc.; Universidade Federal de Santa Catarina

ricomanhaes@gmail.com

VIEIRA, Milton; Dr.; Universidade Federal de Santa Catarina

milton.vieira@ufsc.br

NASSAR, Victor; Dr.; Universidade Federal de Santa Catarina

victornassar@gmail.com

NISHIDA, Jonathan; M. Sc.; Universidade Federal de Santa Catarina

jounishida@gmail.com

\section{Resumo}

Quadrinhos e storyboard apresentam semelhanças em seus conceitos, um representando um conjunto de imagens em sequência para expor uma narrativa. Este artigo analisa de forma comparativa as diferenças existentes entre a linguagem dos quadrinhos e a do storyboard. As soluções gráficas utilizadas em cada uma dessas linguagens, na expressão de seus conteúdos, foram comparadas descritivamente. Assim, são analisadas as características de cada um, divididas em: 1) Formato e dimensões; 2) A representação do áudio; 3) A representação do movimento; 4) Os planos e ângulos de visão; e 5) As legendas. Características como o formato horizontal, e o áudio, as figuras cinéticas, as metáforas visuais e as legendas, quando colocadas lado a lado, evidenciaram as diferenças e as semelhanças entre os dois métodos.

Palavras Chave: História em Quadrinhos; Storyboard; Mídia.

\begin{abstract}
Comics and storyboard present similarities in their concepts, representing a set of images in sequence to expose a narrative. This paper analyzes in a comparative way the differences between the language of comics and that of storyboard. The graphic solutions used in each of these languages, in the expression of their contents, were compared descriptively. Thus, the characteristics of each one are analyzed, divided into: 1) Format and dimensions; 2) The representation of the audio; 3) The representation of the movement; 4) The planes and viewing angles; And 5) The subtitles. Features such as the horizontal format and audio, kinetic figures, visual metaphors and legends, when placed side by side, evidenced the differences and similarities between the two methods.
\end{abstract}

Keywords: Comics; Storyboard; Media. 


\title{
1 Introdução
}

Os modelos de um storyboard e os de quadrinhos apresentam semelhanças entre os métodos, utilizando ilustrações ou vinhetas, dispostas em sequência, para narrar uma história. $\mathrm{Na}$ análise destes dois métodos, é possível observar particularidades nas soluções encontradas para a transmissão de seus conteúdos. As diferenças entre eles estão identificadas tanto nos formatos como nos suportes de mídias: analógica e digital; vertical em papel e horizontal em vídeo.

Assim como define Moya (1972), a aproximação entre o cinema e os quadrinhos é inevitável, pois os dois surgiram da preocupação de representar e dar sensação de movimento. Os quadrinhos, como o próprio nome indica, são um conjunto de imagens em sequência. $O$ que faz do bloco de imagens uma série é o fato de que cada quadro ganha sentido depois de visto o anterior; a ação contínua estabelece a ligação entre as diferentes figuras. De modo semelhante, de acordo com Hart (1999), o storyboard apresenta quadros em sequência com desenhos adaptados do roteiro de um filme.

A diferença evidenciada entre a história em quadrinhos e o storyboard está na finalidade dos dois. Enquanto os quadrinhos são considerados como um produto concreto, o storyboard é uma pré-visualização de um produto que ainda será concretizado em forma de vídeo. Assim, no storyboard, o desenho não precisa estar totalmente acabado, pois representa apenas um esboço do fluxo da história, apresentando os personagens, uma ideia dos enquadramentos, dos movimentos de câmera e dos pontos de vistas (CESCONETTO, 2006). Já em relação aos quadrinhos, o autor precisa que a arte esteja finalizada, para que possa ser disponibilizada como produto ao público.

A partir deste contexto, este artigo objetiva analisar as diferenças e semelhanças existentes entre a linguagem dos quadrinhos e a do storyboard, comparando as soluções gráficas utilizadas em cada uma dessas linguagens, na expressão de seus conteúdos. Assim, são analisadas a seguir as características de cada um, divididas em: 1) Formato e dimensões; 2) A representação do áudio; 3) A representação do movimento; 4) Os planos e ângulos de visão; 5) As legendas.

\section{Os elementos que compõem as histórias em quadrinhos e o storyboard}

Assim como qualquer linguagem artística, os quadrinhos e o storyboard possuem mecanismos que auxiliam na expressão de seu conteúdo.

Em relação às histórias em quadrinhos, considera-se que:

\begin{abstract}
A imagem desenhada é o elemento básico [...]. Ela se apresenta como uma sequência de quadros que trazem uma mensagem ao leitor, normalmente uma narrativa, seja ela ficcional (um conto de fadas, uma história infantil, a aventura de um super-herói etc.) ou real (o relato/reportagem sobre fatos ou acontecimentos, a biografia de um personagem ilustre, etc.). Sua menor unidade narrativa será o quadrinho ou vinheta. A sucessão de vinhetas será, no mundo ocidental, organizada no sentido da leitura do texto escrito, ou seja, do alto para baixo e da esquerda para a direita (nos países asiáticos, essa representação ocorrerá da direita para a esquerda, acompanhando a leitura das escritas japonesa e chinesa, por exemplo) o que permitirá o entendimento da mensagem (RAMA, VERGUEIRO 2008).
\end{abstract}

A origem do termo storyboard é inglesa e vem da junção das palavras Story e Board, que significam respectivamente história e painel, definindo de maneira direta o formato dessa 
ferramenta - um painel onde se narra visualmente a história a partir do roteiro escrito:

O Storyboard é uma ferramenta de pré-visualização que apresenta quadro a quadro e em sequência, desenhos adaptados do roteiro de uma animação ou um filme. São ilustrações conceituais que ajudam a esclarecer e a fortalecer a narrativa do roteiro. O objetivo é facilitar para a equipe de produção o trabalho de organização requerido pelo roteiro em uma cena. O Storyboard deve ser necessariamente criado antes de começarem as gravações, de modo que o resultado final da cena seja o mais próximo possível do esperado pelo roteirista (HART, 1999).

Observa-se na Figura 1 um exemplo de uma página de história em quadrinhos e de storyboard. Essas páginas serão usadas na demonstração das características empregadas em cada linguagem.

Figura 1 - Exemplo de uma página de quadrinhos e um storyboard

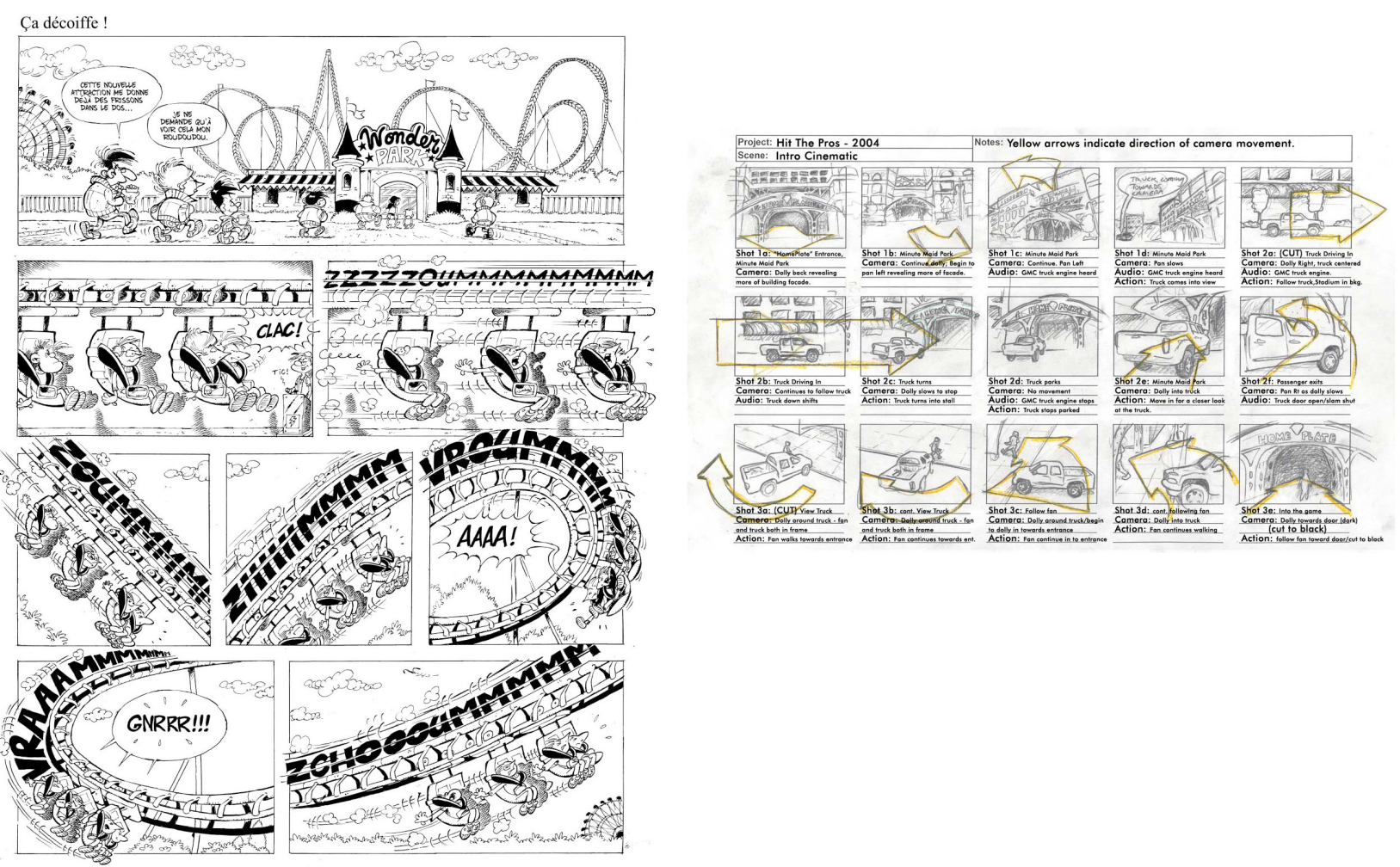

Fonte: Os autores e Lewis (2004).

A seguir, será analisado, de modo comparativo, cada uma dessas ferramentas e suas funções, tais como: 1) O formato e dimensões; 2) A representação do áudio; 3) A representação do movimento; 4) Os planos e ângulos de visão; e 5) As Legendas.

\subsection{Formatos e dimensões}

Por se tratar de linguagens gráficas, as histórias em quadrinhos, assim como o storyboard, funcionam inseridas em suportes (papéis, telas de computador ou tablets) que por sua vez possuem formatos e dimensões pré-estabelecidos, e reconhecidas como ponto de partida para a criação. 
a) Formato nos quadrinhos:

Para a conceituação de quadrinhos ou vinhetas, considera-se:

O quadrinho ou vinheta constitui a representação, por meio de uma imagem fixa, de um instante específico ou de uma sequência interligada de instantes, que são essenciais para a compreensão de uma determinada ação ou acontecimento. Isso quer dizer, portanto, que um quadrinho se diferencia de uma fotografia, que capta apenas um instante, um átimo de segundo em que o diafragma da máquina fotográfica ficou aberto. Assim, dentro de um mesmo quadrinho podem estar expressos vários momentos, que, vistos em conjunto, dão a idéia de uma ação específica. Nos quadrinhos que refletem luta, comuns nas histórias de aventura, pode-se retratar, em um mesmo quadro, tanto o momento do impacto do soco que um personagem dá em outro como os momentos que antecedem essa ação ou acontecem em decorrência desse ato: as palavras de ameaça do agressor, o grito da vítima e o início de sua queda, depois da agressão sofrida." (RAMA, VERGUEIRO 2008).

A página de quadrinhos tem como finalidade a impressão em papel, seja ela em uma revista, um livro ou jornal. As publicações do gênero apresentam, em sua maioria, formatos de impressão em tamanho A4 $(297 \times 210 \mathrm{~mm})$ ou A5 $(210 \times 148 \mathrm{~mm})$. Além desses dois formatos principais, existe formato de tira, que é definida pelo Dicionário Houaiss da Língua Portuguesa como: "segmento ou fragmento de história em quadrinhos, geralmente com três quadros, e apresentado em jornais e revistas numa só faixa horizontal. Observam-se exemplos desses formatos na Figura 2.

Figura 2 - Exemplos dos três formatos mais conhecidos, A4, A5 e Tira.
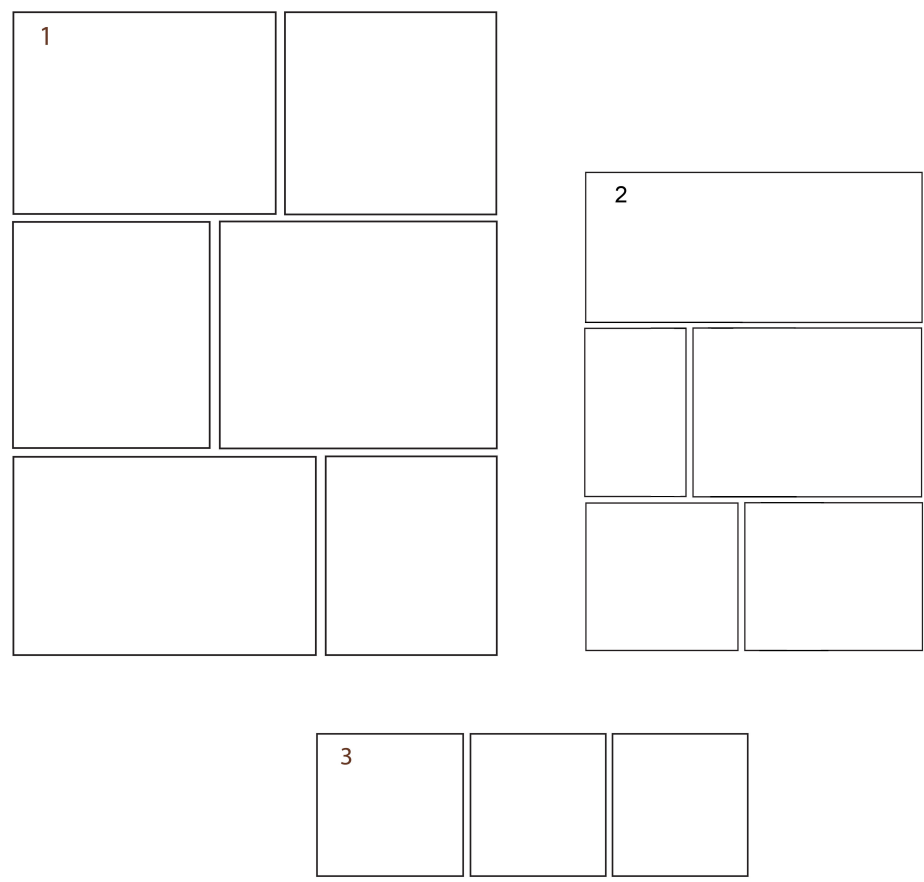

Fonte: Os autores. 
b) Formato do storyboard:

Assim como nos quadrinhos, as vinhetas do storyboard mostram a sequência de uma cena, porém os quadros devem apresentar o formato final de exibição, podendo ser de um em um ou até quatro por página. "Os formatos são os seguintes: o formato de TV em 1.33:1, o formato standard $16 \mathrm{~mm}$ em 1.66:1, o formato tela plana em 16/9 1.78:1 associado ao formato HDTV $1920 \times 1080$ pixels." (BEGLEITER, 2001).

Pode-se observar o exemplo na Figura 3.

Figura 3 - Exemplos de formatos de storyboard.

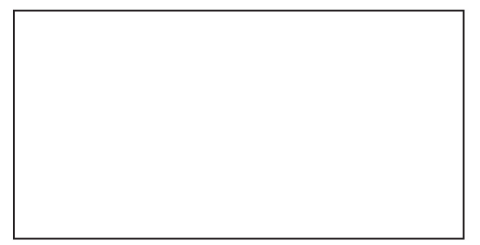

Plano:

Áudiol:

Áudio2:

áudio3:.

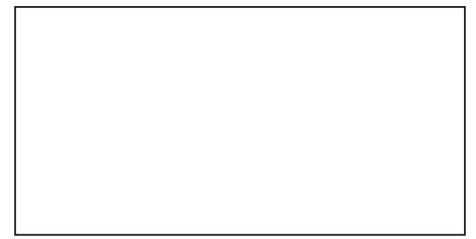

Plano:

Áudiol:

Áudio2:

áudio3:.
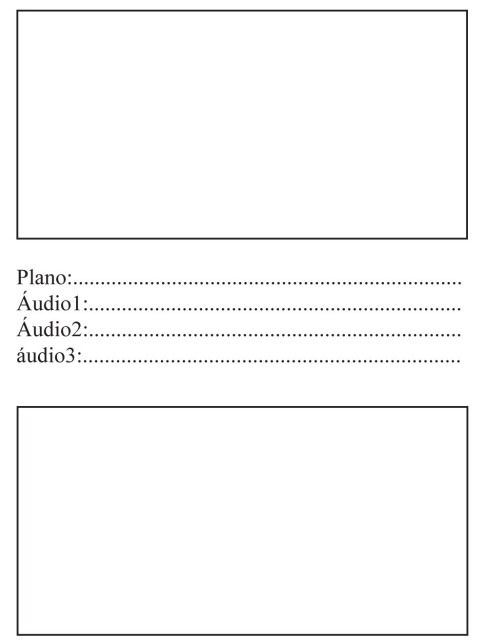

Plano:

Áudio 1

Áudio2

áudio3:.

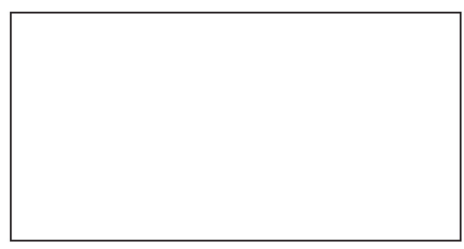

Plano:...........

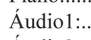

Áudio2:

$\ldots$

áudio3

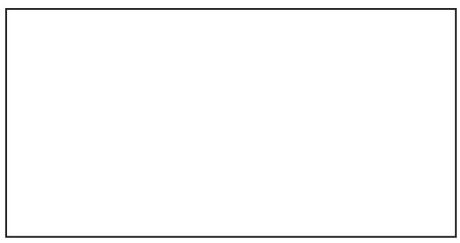

Plano:

Áudio1:

Áudio2

áudio3:.........

Fonte: Os autores.

\subsection{A representação do áudio}

a) Representação do áudio nos quadrinhos:

Outra distinção entre quadrinhos e storyboard, encontra-se no som. Nos quadrinhos, os sons podem ser expressos por onomatopeias, inseridas dentro das vinhetas ou quadrinhos. As onomatopeias representam imitação de sons por meio das palavras.

Grafadas fora dos balões, as onomatopéias são representadas originando-se próximas à fonte sonora que representam. São também, ferramentas gráficas interessantes. "Nos mangás, por exemplo, as onomatopéias são integradas ao desenho de uma tal forma que sua tradução e substituição pode quebrar a harmonia do conjunto visual. (RAMA, VERGUEIRO 2008).

Observa-se a Figura 4, com exemplo de aplicação de onomatopeias em quadrinhos, em que se pode perceber e ler os sons da montanha russa presentes nas figuras, com as palavras "zoummm", "zimmmm" e "vroummm". 
Figura 4 - Exemplo de onomatopeias em quadrinhos.
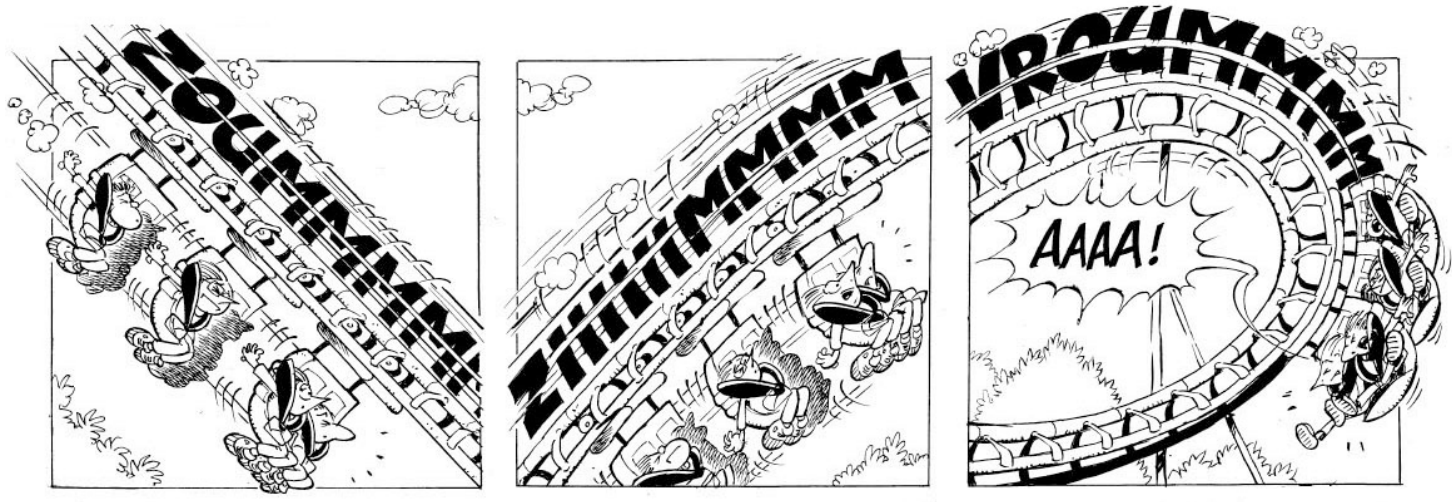

Fonte: Os autores.

Outra forma de representação de áudio mais conhecidas nos quadrinhos é o balão. Dentro dele são inseridos os diálogos dos personagens. Os balões são desenhados da esquerda para a direita seguindo a ordem dos diálogos. “... principalmente pelo balão, as histórias em quadrinhos se transformam em um verdadeiro híbrido de imagem e texto. $O$ balão é a intersecção entre imagem e palavra." (RAMA, VERGUEIRO 2008 p.56). Estes podem ser representados de várias maneiras. Por exemplo, quando expressam um pensamento são desenhados em forma de nuvem. Quando expressam o som oriundo de um rádio ou televisão, são desenhados com pontas várias agudas. Para expressar um grito, as letras são desenhadas em tamanho grande. E para expressar um sussurro as bordas do balão são tracejadas.

b) Representação do áudio no Storyboard:

O áudio está presentes nos filmes como trilha sonora, um diálogo, ou foleys (sons do ambiente de uma cena). Dessa forma, o som passa a ser previsto já na concepção de um storyboard, indicados em caixas de texto abaixo da imagem. A ordem, no caso dos diálogos, é indicada pela nominação de cada diálogo. Observa-se o exemplo na Figura 5, a descrição do áudio pode ser percebida pela descrição presente na terceira linha das indicações textuais externas às figuras do storyboard. 
Figura 5 - Exemplo de onomatopeias em quadrinhos.

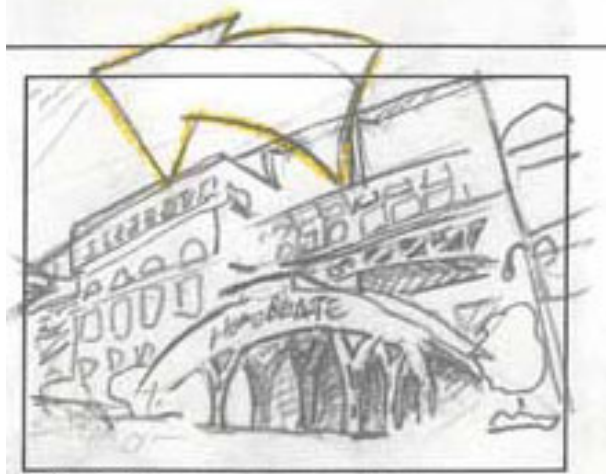

Shot 1c: Minute Maid Park Camera: Continue. Pan Left Audio: GMC truck engine heard

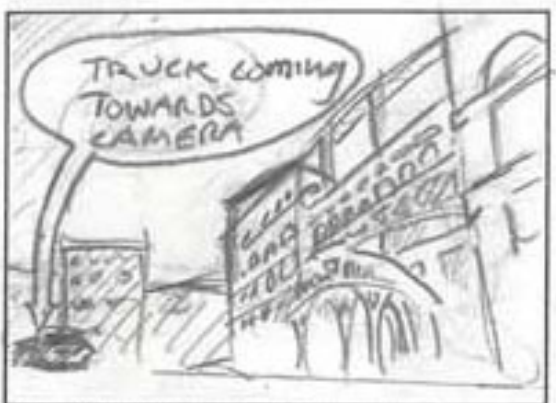

Shot 1d: Minute Maid Park Camera: Pan slows Audio: GMC truck engine heard Action: Truck comes into view

Fonte: Lewis (2004).

\subsection{A representação do movimento}

a) Representação do movimento nos quadrinhos:

Para resolver a compreensão da noção de movimento e velocidade na narrativa dos quadrinhos, utilizam-se linhas de ação, que vêm a ser figuras cinéticas que expressam movimento. "Alguns pesquisadores argumentam que essas linhas estão diretamente ligadas ao rastro gerado pelo sistema visual quando acompanhamos um objeto com os olhos" (COHN, MAHER, 2015). Nos quadrinhos as linhas de ação (traços longos que partem do objeto em movimento) geralmente estão inseridas harmoniosamente dentro da cena, de maneira a também complementar esteticamente a ilustração. Observa-se o exemplo na Figura 6, no qual as linhas de ação e movimento partem da esquerda dos objetos, mostrando movimento para a direita da vinheta.

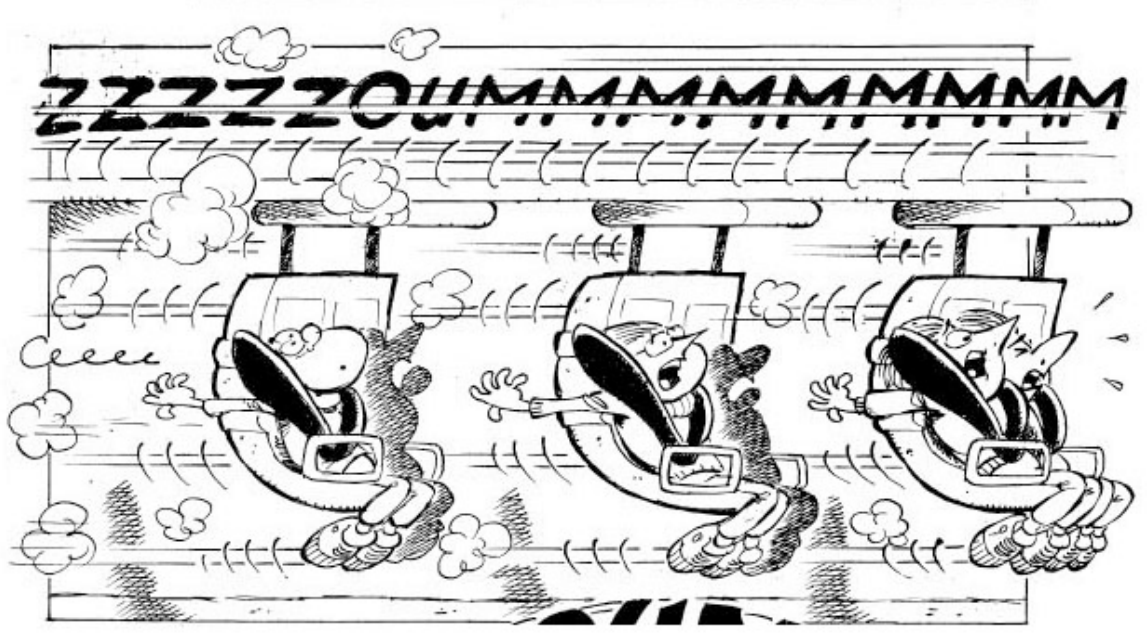

Fonte: Os autores. 
b) Representação do movimento no storyboard:

No Storyboard, são utilizadas setas, que são inseridas na própria imagem ou posicionadas externamente (lateralmente, abaixo e acima), associadas aos quadros ou vinhetas explicitando os movimentos de câmera e de personagens. Pode-se observar o exemplo na Figura 7, em que há uma seta de um quadro a outro, indicando a movimentação que o carro deve fazer. Além disso, pode haver um texto explicando a ação da cena, a fim de facilitar a condução do storyboard.

Figura 7 - Exemplos de expressão do movimento no storyboard.

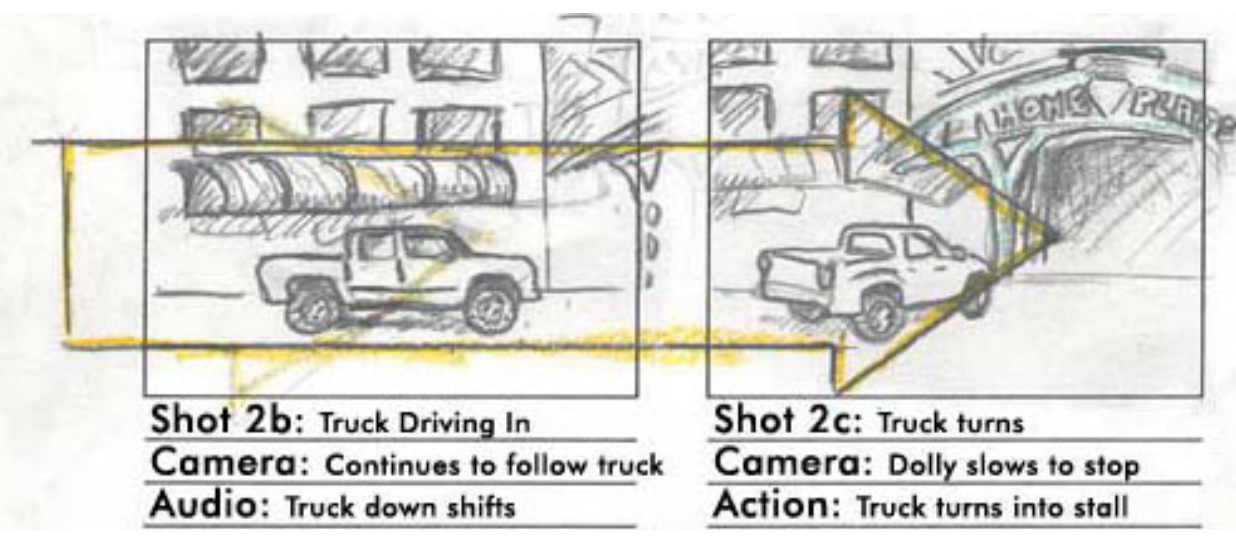

Fonte: Lewis (2004).

\subsection{Os planos e ângulos de visão}

a) Os planos e ângulos de visão nos quadrinhos

Segundo Rama e Vergueiro (2008), nos quadrinhos, os planos recebem a mesma denominação derivada do cinema. Para os planos: o plano geral, o plano de conjunto, o plano médio, o plano americano, primeiro plano e plano de detalhe ou close-up. Para os ângulos de visão: o ângulo de visão médio, o de visão superior e o de visão inferior. Observa-se na figura 8 a página de quadrinhos, em que se pode perceber diversos ângulos de câmera e planos de "filmagem. 
Figura 8 - Página com a presença de diferentes planos.
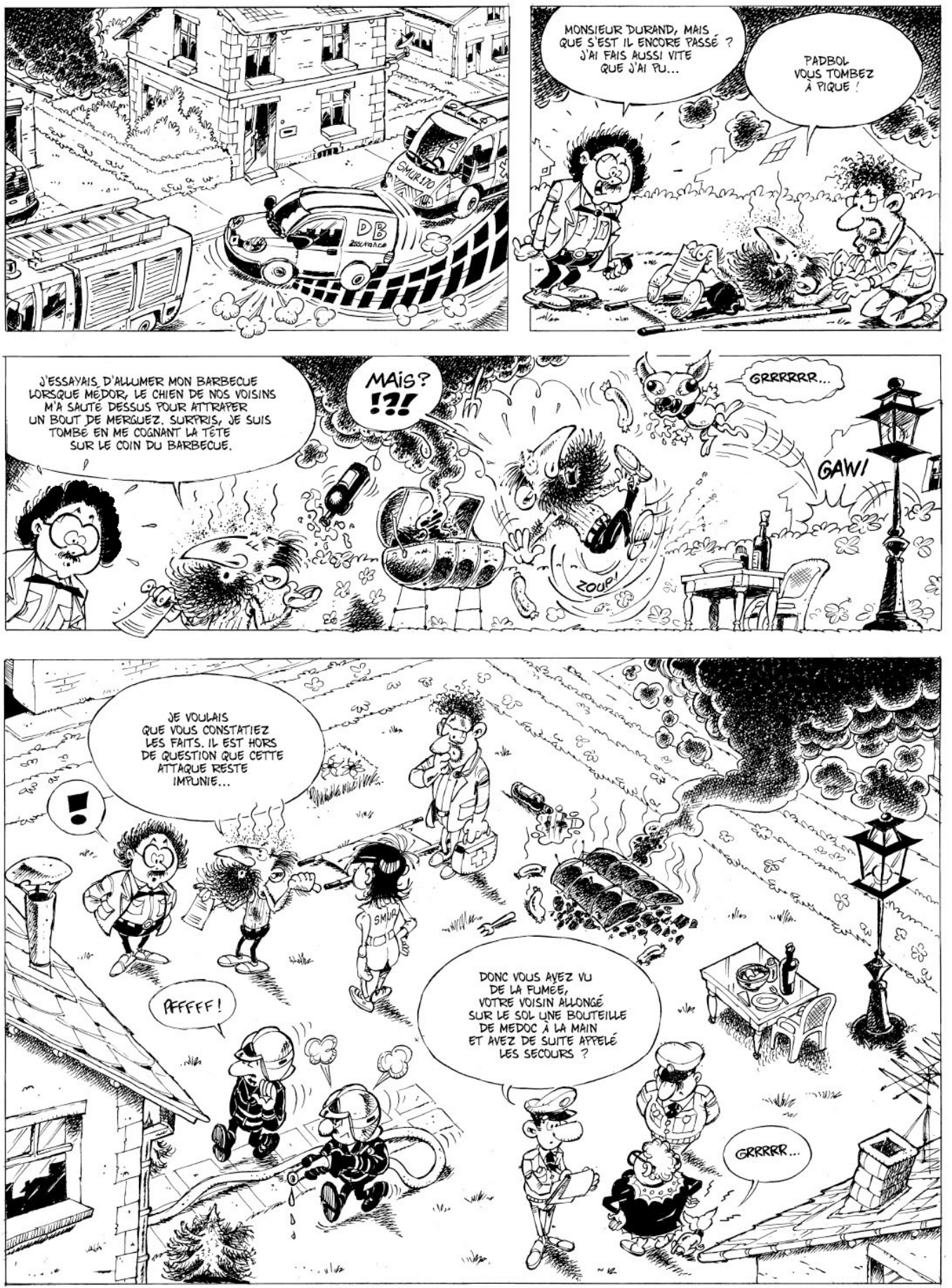

Fonte: Os autores.

b) Os planos e ângulos de visão no storyboard:

Como os planos e ângulos de visão dos quadrinhos derivam do cinema, as mesmas aplicações são encontradas no storyboard, podendo ser representados em diferentes quadros, indicando como a cena deve ser filmada. 
Figura 9: Exemplos de ângulos e planos de "filmagem".

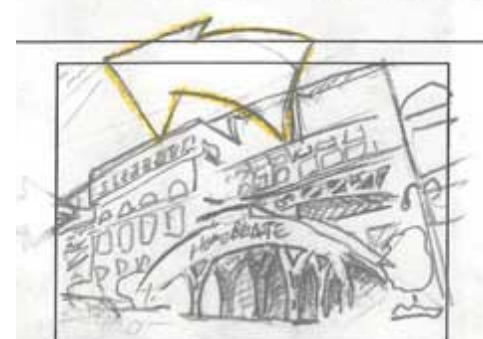

Shot 1c: Minute Maid Park Camera: Continue. Pan Left

Audio: GMC truck engine heard

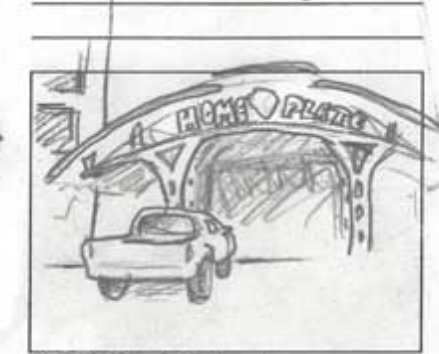

Shot 2d: Truck parks

Camera: No movement

Audio: GMC truck engine stops

Action: Truck stops parked

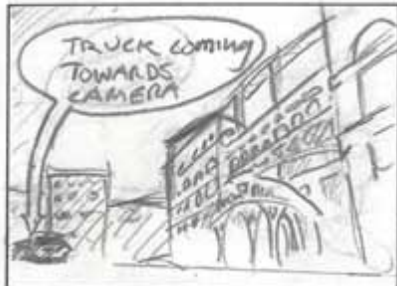

Shot 1d: Minute Maid Park

Camera: Pan slows

Audio: GMC truck engine heard

Action: Truck comes into view

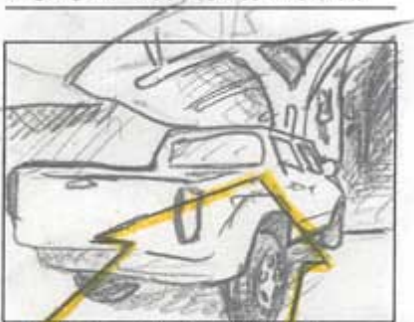

Shot 2e: Minute Maid Park

Camera: Dolly into truck

Action: Move in for a closer look at the truck.

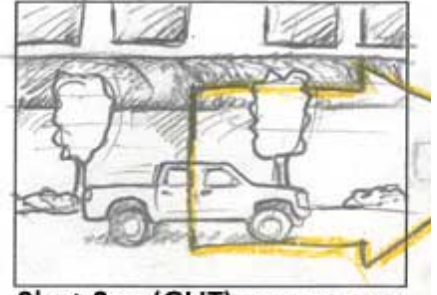

Shot 2a: (CUT) Truck Driving In

Camera: Dolly Right, truck centeres

Audio: GMC truck engine.

Action: Follow truck, Stadium in bks

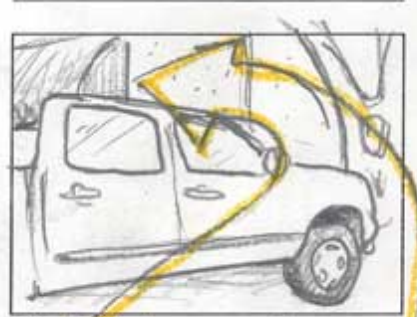

Shot 2f: Passenger exits

Camera: Pan Rt as dolly slows

Audio: Truck door open/slam shut

Fonte: Lewis (2004).

\subsection{As legendas}

a) A legenda nos quadrinhos:

Para Rama e Vergueiro (2008), a legenda representa a voz onisciente do narrador da história. É utilizada para situar o leitor no tempo e no espaço. É colocada na parte superior do quadrinho. Observa-se o exemplo na Figura 10, na parte superior esquerda do quadro.

b) A legenda no storyboard:

A legenda no storyboard pode ser interpretada como a voz do narrador do filme, como uma fala que irá compor a cena. Portanto, é indicada nas linhas do áudio, abaixo do storyboard. 


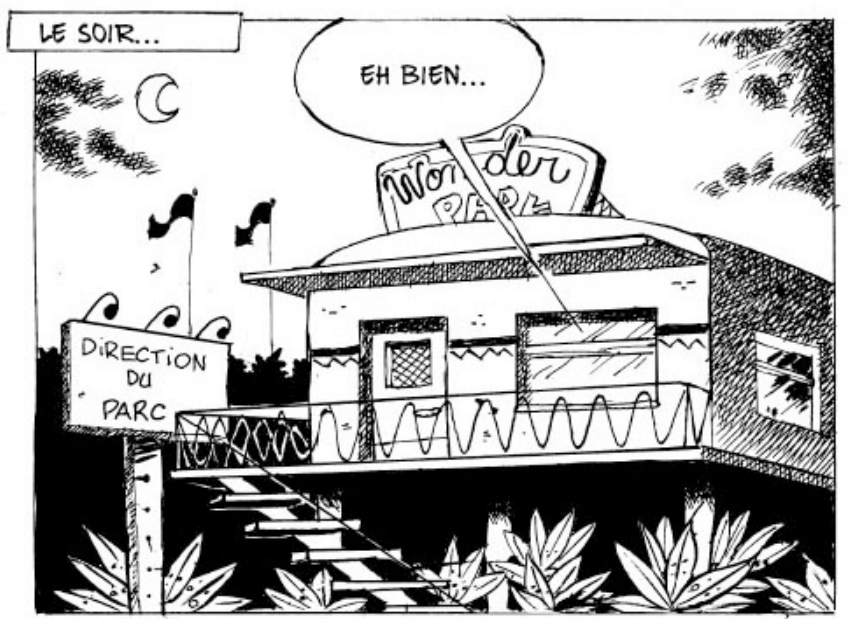

Fonte: Lewis (2004).

\section{Considerações finais}

Considerando que existem duas linguagens, quadrinhos e storyboard, cujo objetivo é a comunicação de conteúdos visuais, esta pesquisa propôs a análise comparativa entre os dois, a partir dos elementos: 1) O formato e dimensões; 2) A representação do áudio; 3) A representação do movimento; 4) Os planos e ângulos de visão; e 5) As Legendas.

Embora apresentem semelhanças, para estabelecer uma migração de páginas de quadrinhos para o formato de storyboard, por exemplo, a fim de promover seu emprego em uma animação, é necessário realizar diferentes adaptações. Durante o tópico comparativo entre os elementos que compõem os dois modelos, pôde-se destacar duas das diferenças mais significativas e que representam desafios para a adaptação de um história em quadrinhos para o modelo de um storyboard,: o formato final dos quadros ou vinhetas e o modo de expressão do áudio.

Nos quadrinhos, os quadros ou vinhetas podem ter dimensões diferentes segundo a necessidade e vontade do autor. Pode-se dizer que nos quadrinhos utiliza-se, por exemplo, um quadro ou vinheta vertical no intuito de evidenciar a altura e a grandiosidade de um determinado cenário ou ação. O mesmo recurso pode também ajudar a evidenciar a velocidade de um movimento em determinada cena. Essa liberdade criativa, dos quadrinhos, facilita a obtenção de dinamismo no resultado definitivo da cena. Porém, esse recurso não pode ser, de modo geral, utilizado na linguagem de storyboard, visto que seu resultado final deve obedecer o formato da tela de televisão ou de cinema. Esse fato obriga o autor, de um modo ou de outro, a uma adaptação da cena, não por meio da dimensão ou formato de quadros ou vinhetas mas da alteração dos planos e ângulos de visão da cena. Se nos quadrinhos esta cena é representada, em toda a sua ação, em um único quadro vertical, no storyboard a mesma cena deverá ser decomposta em diversos quadros ou vinhetas com diferentes ângulos de visão.

Em relação ao áudio, nos quadrinhos podem-se utilizar as onomatopeias como recurso 
para a expressão dos barulhos de uma cena. Neste caso, a grafia dos sons pode ser considerada um elemento importante na representação visual. Nos quadrinhos, a onomatopeia, além de ter a função de expressão sonora, é também um elemento gráfico de importância estética para a afirmação do estilo de desenho e dinâmica do som expressado. O fato da linguagem de storyboard não contar com o recurso das onomatopeias pode significar um desafio durante a adaptação de uma página de quadrinhos para o storyboard. Enquanto nos quadrinhos, a onomatopeia representava um elemento gráfico potencializador da expressão da cena e do som, para o storyboard, a representação é indicada textualmente e de modo complementar à cena, o que pode significar perdas de determinados sentidos e, por consequência, problemas de adaptação.

Por fim, espera-se que este artigo possa ter contribuído enquanto análise descritiva de cada um dos modelos, quadrinhos e storyboard, apresentando semelhanças e diferenças capazes de auxiliar no entendimento das linguagens e nos desafios que representam para adaptações.

\section{Agradecimentos}

Agradecemos a equipe do DesignLab da Universidade Federal de Santa Catarina, pelo apoio durante o projeto, o CNPQ e a Capes pela disponibilização de Bolsas de estudo.

\section{Referências}

BEGLEITER, Marcie. From word to image: storyboarding and the filmmaking process. Studio city, Calif.: Michael Wiese Productions, 2001.

CESCONETTO, Charles. Desenho e animação. Palhoça: Unisul Virtual, 2006. 244 p.

COHN, Neil; MAHER, Stephen. The notion of the motion: The neurocognition of motion lines in visual narratives. San Diego, Calif.: brain research, v. 1601, p. 73-84, 2015.

HART, John. The art of the storyboard: storyboarding for film, TV, and animation.Boston: McGraw Hill Professional, 1999.

HOUAISS, Antônio; VILLAR, Mauro de Salles. Dicionário Houaiss da Língua Portuguesa. Rio de Janeiro: Objetiva, 2001. v. 200.

MOYA, Álvaro de. Shazam. 2. ed. São Paulo: Perspectiva, 1972. 346 p.

LEWIS, Peter. In: Peter Lewis Portfolio. Primitive-Eye. 2004.

RAMA, Angela; VERGUEIRO, Waldomiro. Como usar as histórias em quadrinhos na sala de aula. São Paulo: Contexto, 2004. 